\title{
Editorial Introduction-25 Years of AGM Theory
}

\author{
Eduardo Fermé · Sven Ove Hansson
}

Published online: 26 February 2011

(C) Springer Science+Business Media B.V. 2011

Twenty-five years have passed since the publication of "On the logic of theory change: Partial meet contraction and revision functions" by Carlos Alchourrón (1931-1996), Peter Gärdenfors, and David Makinson (AGM) [1]. In order to celebrate the anniversary we have brought together a group of leading scholars in the field to comment on some of the many developments and ramifications that have their origin in the 1985 paper.

We are particularly proud to have both Peter Gärdenfors and David Makinson among the contributors. Gärdenfors shares his memories of the background and early history of AGM theory. Makinson provides an introduction to the as yet largely unexplored connections between belief revision and probability theory.

Hans Rott discusses two classical issues in the AGM literature, Ramsey conditionals and iterated belief change, proposing a way to reconcile the Ramsey test for conditionals with AGM-style revision.

Richard Booth and Thomas Meyer propose a way to represent iterated revision, employing enriched epistemic states that make it possible to go beyond the first revision step of the revision operator.

Sébastien Konieczny and Ramón Pino Pérez provide an overview over belief merging and point out important connections between merging and social choice theory.

E. Fermé $(\bowtie)$

Madeira Interactive Technologies Institute, University of Madeira,

Campus Universitário da Penteada, 9000-390 Funchal, Portugal

e-mail: ferme@uma.pt

S. O. Hansson

Division of Philosophy, Royal Institute of Technology, Stockholm, Sweden

e-mail: soh@kth.se 
Renata Wassermann investigates how AGM can be applied to non-classical logic, focusing on how to deal with non-classical behaviour of negation.

Finally, this issue contains an attempt to summarize major developments in twenty-five years of AGM-inspired research. In preparing it we benefited from the help of more than fifty colleagues who answered our queries and provided us with information. Several of them also acted as referees for the articles in this issue. In addition to its academic excellence, the belief revision community is a remarkably generous one. This bodes well for the next quarter century of belief revision research.

\section{Reference}

1. Alchourrón, C., Gärdenfors, P., \& Makinson, D. (1985). On the logic of theory change: Partial meet contraction and revision functions. Journal of Symbolic Logic, 50, 510-530. 